\title{
Crónica de la minería de oro en Colombia: de la montaña al texto
}

\author{
Juan Felipe Hernández Gómez/ University of British Columbia
}

\section{Resumen}

Este artículo evalúa la historia literaria minera del pueblo minero de Marmato, Colombia. Partiendo de novelas como Tierra virgen (1897) de Eduardo Zuleta, La bruja de las minas (1938) de Gregorio Sánchez, trazo una línea que sigue la evolución de la literatura minera en Colombia rastreando sus especificidades históricas y culturales. Introduzco el término "Minería Tropical" para categorizar algunas de estas particularidades. Concluyo con una discusión sobre el documental Marmato (2014) que representa el fin del discurso de la minería tropical como tal y toma un giro hacia discursos representacionales más complejos revelando una serie de actores sociales que luchan por poder y reconocimiento usando otros medios y técnicas.

Palabras clave: Literatura antioqueña, Recursos naturales, Conflictos de recursos, Literatura de minería, neoliberalismo.

\begin{abstract}
This article discusses the literary history of the goldproducing town Marmato, Colombia. Taking my cue from novels such as Tierra virgen (1897) by Eduardo Zuleta and La Bruja de las Minas (1938) by Gregorio Sanchez, I offer an overview that follows the evolution of mining literature in Colombia by tracing its historical and cultural specificities. I put forward the term "Tropical Mining" to categorize some of these historic and cultural specificities. I conclude by offering a reading of the documentary Marmato (2014) which departing from "tropical mining" depicts a complex field of actors as they vie for acknowledgement and power using new means and techniques.
\end{abstract}

Keywords: Antioquia literature, Natural resources, Resource conflict, mining literature, Neoliberalism.
Este artículo investiga la historia literaria de la pequeña ciudad minera de Marmato, Caldas, ubicada en los Andes colombianos y conocida por su riqueza aurífera. La tradición extractiva de Marmato, junto con su prominencia histórica en la conciencia literaria de escritores y recientemente de cineastas, permite un análisis significativo sobre la problemática de la literatura de la extracción mineral en el país. Baso mi debate en textos literarios y un documental relacionados con la extracción y sus consecuencias sobre la vida humana y no humana en la región. Sostengo que al releer las siguientes obras asistimos a la evolución de una perspectiva narratológica que se elabora primero desde una visión romantizada de la naturaleza y lo nacional-popular para luego devenir en una perspectiva cada vez más antagónica y autoconsciente. Mi objetivo es re-contextualizar, a través de la literatura, un mundo minero perdido y dar cuenta del cambio de discursos literarios acerca de la extracción de minerales en su estado actual dentro del país y la región en general.

Para entender mejor estos textos, empleo la noción de "minería tropical" que puede ser entendida como un concepto doble formado por (1) una forma discursiva especifica de representación sobre procesos y relaciones de producción que forman la cultura minera de acuerdo a los autores estudiados y (2) una cultura de extracción mineral que se diferencia cualitativamente de otras que también emergen alrededor de la extracción pero no caben dentro del rubro tropical y cuentan con sus propias características sociales y culturales. ${ }^{1}$

Uso el término "discursividad" en el sentido genealógico articulado por Michael Foucault no para hacer referencia a aspectos lingüísticos formales del mismo, sino a patrones institucionalizados de conocimiento que operan gracias al enlace conocimiento/poder.

La minería tropical puede ser pensada como funcionalidad de representación que enfatiza y celebra algunos aspectos mientras matiza otros. Como discurso, enmarca de manera general el trabajo manual de extraer mineral como goce, da primacía a los sentidos como medios de percepción y expresión y representa de manera exotizante el mundo que rodea la extracción como colorido, sensual y misterioso. Naturalmente, esta líneas narrativas no son inocentes ni ocurren en un vacío ideológico sino que usan recursos retóricos específicos como el exotismo, la mirada exterior en relación con el conocimiento/poder, y la romantización del referente para maximizar el efecto y el afecto sobre el lector $\mathrm{y}$ un orden social determinado. 
Por otra parte, localizo la minería tropical en el sentido de acontecimiento económico-histórico como nodo y articulación dentro de esa red global del capitalismo decimonónico en Latinoamérica propuesta por Jennifer L. French en su Nature, Neocolonialism and the SpanishAmerican Regional Writers (2005), donde bajo el concepto de Imperio Invisible ella describe la formación de una manera muy particular de expandir el imperio y los límites del capital. Según su tesis el neo-colonialismo británico constituyó un Imperio Invisible porque sus medios y fines eran enteramente económicos y al contrario de los norteamericanos, su política exterior no recurría a intervenciones abiertas que pudieran alienar la opinión pública o causar conflictos prolongados. Las prácticas económicas y sociales que dan lugar a lo que llamo minería tropical podrían entenderse como fenómenos que desde su especificidad configuran esta red global. ${ }^{2}$

En las narrativas estudiadas, el discurso de minería tropical se caracteriza por enfatizar un ambiente natural relativamente benevolente; relaciones de trabajo que aunque claramente explotadoras, no son totalmente opresivas vis-àvis otros mineros y administradores y el uso del humor. Así mismo este mundo de minería tropical abarca una cultura que concibe la extracción de minerales más como una oportunidad para avanzar de posición social en lugar de percibirla y denunciarla como una forma de esclavitud moderna. Este último es el caso más generalizado en las narrativas más conocidas en la región que nos llegan desde Bolivia, Chile y Perú, donde la explotación mineral de larga data está marcada por un aire de pesimismo y derrotismo a pesar de una relación más cercana y productiva entre las narrativas mineras o la cultura literaria y el devenir de la historia política de cada país: en Bolivia las narrativas de escritores mineros o pro-mineros como Metal del diablo (1946) de Augusto Céspedes prefiguraron el advenimiento de la Revolución de 1952 movilizando opiniones en la multitud abigarrada y creando simbolismos populares a favor de la causa de los mineros. En Chile, las narrativas del Norte Grande como Hijo del salitre (1952) de Volodia Teitelboim novelaron la vida de Luis Emilio Recabarren, figura clave del movimiento obrero chileno revolucionario izquierdista. En la literatura minera de los países andinos la representación del minero ocurre mayormente como sujeto fuerte físicamente pero desarraigado del ayllu y oprimido por el orden socioeconómico dominante típico de un campo minero. ${ }^{3}$ En pocas palabras, la minería es presentada casi como una maldición acaecida sobre sujetos-victimas, quienes tienen poca esperanza en el estado o en sus patrones a la hora de mejorar condiciones. Los narradores de la minería andina trasladan al régimen de la representación estos rasgos individuales y colectivos para dar cuenta de la situación de atraso, como es el caso de Bolivia, y de estimular debates desarrollistas y positivistas que datan desde principios del siglo XX.

En el caso colombiano, parte de lo que yo llamo minería tropical incluye la recurrencia de patrones retóricos que quieren poner en relieve convenciones sociales relativamente liberales. Por ejemplo el hecho de permitir que las mujeres trabajen en los sitios mineros; la presencia de criollos, indígenas, afrodescendientes y todo tipo de sujetos interesados en el comercio; la convivencia de diferentes actividades económicas apoyando lugares predominantemente mineros. Todos estos aspectos se encuentran en las narrativas de escritores canónicos como La marquesa de Yolombó (1928) o Hace tiempos (1936) de Tomás Carrasquilla, así como en Tierra virgen (1897) de Eduardo Zuleta, La bruja de las minas (1938) de Gregorio Sánchez Gómez, o los cuentos de Efe Gómez.

\section{Las dichas de la Minería Tropical}

Uno de los pocos escritores interesados en minerales y literatura en Antioquia es Tomás Carrasquilla. Aunque su experiencia directa con la minería fue constante debido a que su familia tuviera concesiones y títulos en Antioquia, la cuestión de la minería sólo se plantea con atención en la novela La marquesa de Yolombó (1926). Sólo comentaré brevemente esta obra -específicamente el tono elogioso en que Bárbara Caballero experimenta la vida en las minas. $L a$ marquesa de Yolombó es la recuperación de una historia de amor y engaño del siglo XVIII que solo se mantuvo viva gracias a la memoria oral antioqueña. El personaje central de la novela es la "Marquesa" Bárbara Caballero, uno de los personajes femeninos mejor definidos en la literatura colombiana. La novela en sí revela un laborioso trabajo de documentación acerca de los discursos y prácticas predominantes en la época sobre el trabajo en las minas locales. Carlos Sánchez Lozano añade: "Esta novela histórica había requerido a Carrasquilla una larga documentación, entrevistas con viejos mineros y campesinos y elaboración laboriosa durante dos años, pero finalmente llevó al autor de Antioquia a alcanzar cierta notoriedad nacional" (Sánchez Lozano 1996, 5).

La marquesa de Yolombó, ejemplifica la representación generalmente positiva de Carrasquilla entorno a las economías mineras locales. Aquí, la extracción mineral suele ser retratada no como esclavitud y condena, sino como una fuente de empleo y como un medio para superar dificultades económicas a través de la educación y una superación personal, como es el caso de Bárbara Caballero, nuestra protagonista pro-monárquica. En la novela, la joven Bárbara es retratada como una adolescente madura de cierto estatus que a los 17 años decide hacer su propio viaje para buscar oro durante cuatro años "haciendo amigos y dinero" (Carrasquilla 1981, 36). Más tarde, a medida que avanza la narración, Caballero es capaz de acumular una fortuna y un ascenso en la sociedad local debido, en gran parte, a sus propias habilidades, su rapidez mental y su voluntad de entrar y trabajar en un mundo dominado por hombres. 
El optimismo implícito en esta literatura paisa o lo que Raymond L. Williams llama la "tradición igualitaria antioqueña" también está presente en el tratamiento de las mujeres dentro de la trama. En claro contraste con la literatura minera que proviene de los Andes (Perú, Bolivia, Chile), la tradición antioqueña representa su papel de manera notablemente diferente: en esta narrativa aparecen dueños y dueñas de minas bastante exitosos como Bárbara Caballero en La marquesa de Yolombó, quien tal vez encarna el paradigma de las mujeres autosuficientes mejor que nadie. También nos encontramos con el caso de Doña Juana, la madre de Manuel, el protagonista de Tierra Virgen quien sacó a su hijo de la pobreza en Remedios, Antioquia comprando acciones en minas locales y luego comprometiéndose a supervisar personalmente la exploración de las vetas de oro. Zuleta escribe: "Incluso los trabajadores admiraban su determinación cuando decían: ¿quién necesita una brújula cuando Doña Juana tiene una comprensión tan clara?" (Zuleta 1978, 169).

El relato tropical de Zuleta ofrece una focalización optimista del impacto de la extracción mineral sobre el ser social de la región: sus escritos transmiten una visión "positiva" (tipificando un enfoque tropical al extractivismo) de la pequeña economía minera como una labor difícil pero edificante. El discurso tropical resurge de muchas maneras en Tierra virgen. En general, Eduardo Zuleta crea un mundo ficticio en el que la explotación minera representa trabajo decente y un medio para lograr la independencia económica. Según Zuleta, los trabajadores no sólo parecen conformes y parcialmente satisfechos con su destino, sino incluso tienden a expresar su lealtad a la mina por encima de otros oficios $\mathrm{u}$ ocupaciones, principalmente porque las minas de oro paradójicamente representan la "libertad". La novela, como toda la literatura de la minería, está siempre atravesada por varios lugares o espacialidades simbólicas. En este caso la narración se inicia en Remedios, una localidad ubicada en el noreste del departamento de Antioquia y cuenta la historia de tres generaciones de una familia antioqueña desde sus humildes comienzos trabajando en las minas de oro hasta su decadente final burgués en Londres. ${ }^{4}$

Para Zuleta, la vida en las minas no es opresiva: los trabajadores soportan una rutina dura pero disfrutan de su experiencia como un todo. Naturalmente, Zuleta retrata el lado oscuro de la minería al describir las riñas inducidas por el alcohol que tienen lugar regularmente durante los días de pago y resultan en un par de heridos o muertos. Pero el lector puede percibir como su voz narrativa se altera afectivamente sobre todo cuando describe los pasajes tropicales que intenta capturar meticulosamente en sus descripciones. En este punto, su voz autoral comienza a estetizar cada elemento que rodea la mina. Zuleta ciertamente se interesa en examinar la naturaleza violenta de los boom towns mineros, pero también en la carga afectiva que la mina ejerce sobre los trabajadores y transitivamente sobre él. Al describir el medio local, utiliza palabras como "cariño" y "afecto" para explicar el apego que sus mineros experimentan cuando se relacionan con el ambiente de la mina y describen una especie de relación simbiótica o complementaria.

Zuleta describe las condiciones adversas en el mundo minero, los túneles, el aire polucionado que se respira allí y el calor sofocante. Pero también y por páginas enteras el entorno general. Al llegar Manuel, el protagonista, a las mina "Juan Criollo" Zuleta explica, "La mina estaba rica y había mucha animación y alegría en el Establecimiento [sic]" (Zuleta 2015, 79). Un año más tarde, cuando éste tiene que abandonar el oficio, agrega, "La vida en las minas tiene un atractivo que inspira la lucha abierta y continua con la naturaleza. El minero es por lo general paciente y abnegado vive alegre y cuando logra aclimatarse no piensa que haya una vida más llena de encantos..." (Zuleta 2015, 89). También, describe el oficio de las mujeres buscando oro en las arenas de los riachuelos cercanos con batea en mano y acompañadas de sus hijas, el sonido de los golpes de los hacheros que derriban los árboles para construir puertas $\mathrm{y}$ atices en los socavones, hormigueando por las faldas de los cerros, cargando maderas pesadísimas al hombro (Zuleta 2015, 81). La ambientación en general sensorial y positiva que Zuleta construye alcanza al sujeto en un pasaje inequívoco. En la novela incluso los mineros ordinarios se elevan a una categoría épica: "Todos tienen un aire de gladiadores" (Zuleta 1978, 152).

El tono acá puede aparecer un tanto grandioso para lectores contemporáneos, pero esta retorica era común entre los ensayistas de finales de siglo. La hipérbole y el exceso de descripción no debe sorprendernos. Como ha señalado Jennifer L. French en Nature, Neocolonialism and the Spanish-American Regional Writers, la prevalencia de las metáforas de la naturaleza en el discurso literario hispanoamericano "fue fundamental para la construcción de una identidad nacional arraigada a la tierra -y no a la fábrica, como se percibía que era el caso en Norteamérica- la principal fuente de productividad" (French 2005, 14). ${ }^{5}$ Zuleta como muchos letrados de su tiempo representa sus sujetos de una manera fuertemente idealizada: guapos, robustos y alegres, se ríen, charlan y cantan mientras trabajan. Y, siguiendo la hipótesis anterior debemos entender que como tales, estos representan el sujeto ideal en la analogía sujeto-nación que se utilizaba ampliamente para construir y representar el proyecto nacional. La tierra representada, o lo telúrico literariamente hablando, ejemplificaban las principales formas económicas del continente y como resultado su gradual incorporación al sistema capitalista internacional, cuestión que como ya sabemos no pasó desapercibida para escritores posteriores.

Mientras que Carrasquilla y Zuleta escriben bajo la conciencia del subdesarrollo, con otros autores como José Eustasio Rivera y los discutidos a continuación, obtenemos un cuadro un poco mas matizado: tal vez una inquietud literalizada debido a la conceptualización de una 
"conciencia de desarrollo". Es decir, una conciencia literaria de un tipo específico de desarrollo, llamémoslo desigual y combinado siguiendo a Trotsky que causa el rompimiento de las relaciones de producción tradicionales existentes. ${ }^{6}$ Hasta fines de la década de 1930 las minas aparecen en la literatura colombiana como un lugar de explotación pero imbuido de posibilidades de libertad de trabajo, la promesa de una fortuna inesperada y una vida en general satisfactoria, a pesar del duro trabajo que requiere el ser minero. Esta discursividad "tropical" entra en crisis y se altera incorporando nuevas intervenciones criticas contra el capital extranjero y el estado con la publicación de La bruja de las minas donde Sánchez Gómez enfatiza la violencia que acompaña los procesos de acumulación y la extracción de oro en Marmato.

\section{Brujas, Bandidos y Británicos}

En su discusión sobre el Imperio Invisible británico, French introduce la apreciación del crítico literario Antonio Cándido sobre la literatura regionalista latinoamericana. Cándido sostiene que la literatura regionalista de los años 1930s y 1940s refleja cierta conciencia sobre el subdesarrollo, porque estos escritores problematizan la relación entre la gente y la tierra que los escritores anteriores habían idealizado o naturalizado. Dice: "No es falso afirmar que la novela adquirió, desde este punto de vista, una fuerza desmitificadora que anticipa el despertar de la conciencia de los economistas y políticos" (citado en French 2005, 28). Yo argumentaría que lo que hace esta literatura (regionalista y telúrica) tan pertinente hoy en día, una literatura que podríamos fácilmente llamar también "literatura neo-colonial global", no es su conciencia del subdesarrollo per se, sino más bien la conciencia de un desarrollo especifico. Un tipo de conciencia literaria, profundamente preocupada por la nueva política económica de principios del siglo XX, que se niega a tratar al minero o al trabajador como un significante idealizado. O un modo de escribir consciente de los efectos desatados del reciente reordenamiento global de la naturaleza y del espacio humano exigido por las leyes de expansión del capital.

Los siguientes dos autores que discutimos aquí ya no representan la extracción como un evento exclusivamente romántico sino como un modo de producción brutal acentuando la violencia asociada con la pobreza, la avaricia, y la experiencia de trabajar dentro de una mina. En otras palabras, el discurso de la minería tropical como lo entendíamos según Zuleta y Carrasquilla entra en una fase de cambio donde como novedad aparecen denuncias contra el capital extranjero y el autoritarismo de estado, pero también figuran continuidades retoricas como el mencionado privilegio que se da a los sentidos, la exotización de sujetos criollos, afrocolombianos e ingleses, y elementos de misterio y erotismo asociados con rituales de origen africano. Propondría acá que La bruja de las minas (1938) de Gregorio Sánchez Gómez, puede ser leída como un texto en transición dentro de paradigmas de representación de la extracción en la literatura colombiana, pues en él conviven aspectos propios del discurso de la minería tropical con nuevas intervenciones retoricas que denuncian la violencia física contra mineros pequeños y medianos y específicamente a nivel de sujeto contra la mujer. En pocas palabras, La bruja de las minas trata de la llegada de una empresa inglesa al pueblo de Marmato y la violencia de las expropiaciones que siguió pero en última instancia puede ser entendida como una historia sobre cómo las mujeres afrontan la carga más pesada en los procesos de la acumulación de capital. Estas dinámicas socio-económicas aparecen en este contexto de transiciones inconclusas entre dos modos de producción; por una parte, la agricultura basada en la hacienda, plantación o la mano de obra artesanal y por otra, la extracción mecanizada y a nivel industrial enfocada en materias primas, principalmente para la exportación. Incrustada en medio de estas dinámicas de explotación inconclusas la novela narra la tragedia de una joven familia propietaria de minas causada por la expropiación de sus títulos y la llegada de una compañía inglesa pero con énfasis en el despojo de una madre y su devenir "bruja" como marginalidad dentro de un orden social de por si inestable y enajenado.

La primera parte de la novela presenta la vida en Marmato antes de la llegada de la empresa extranjera. Se trata de un distrito minero poblado por una serie de pequeños y medianos propietarios de minas como Florencio Botero, el protagonista. Se narra su rutina diaria, las perspectivas inminentes de la transferencia de títulos y termina con la llegada de un destacamento del ejército a mando del General Mandibulas, quien con el pretexto de hacer cumplir la ley, desaloja a los dueños de las minas. La tensión en este episodio se agrava rápidamente cuando Botero durante un forcejeo en el zaguán de su casa es de repente asesinado a tiros delante de su esposa Cecilia y su pequeña hija, Donatila.

Sánchez Gómez estaba interesado en registrar este episodio en su producción literaria porque el pasaje de la novela refiere sin duda a uno de los acontecimientos más importantes de la historia de Marmato: la ocupación violenta ejercida por Eduardo Vásquez Cobo y las tropas del ejército en 1906, en la que trató de monopolizar toda la región productora de oro de Marmato y sus alrededores. ${ }^{7}$ Por cierto, en 1905, un año antes de la ocupación, el hermano de Eduardo Vásquez, que en esa época era ministro de Relaciones Exteriores en Bogotá, hizo la transferencia de su contrato por veinte años a C. W. Syndicate Limited (una transferencia que naturalmente representaba una importante comisión). El profesor Jairo Henry Arroyo Reina explica que "lo que aparece en la novela como la concesión no era más que la apropiación de los recursos minerales nacionales por las corporaciones transnacionales, con la complicidad de los funcionarios estatales haciendo uso de la fuerza y la violencia contra los intereses de sus compatriotas" (citado en Sánchez Gómez 2010, 11). ${ }^{8}$ 
Recordemos que Cecilia y Florencio tenían una hija Donatila, que presenció el asesinato de su padre la mañana del desalojo. De acuerdo con la narración, Cecilia, la madre es llevada media enloquecida por el impacto de este evento, a un barrio de Medellín, mientras que Donatila separada de su madre es enviada a algunos familiares de una ciudad diferente. No se dice más sobre el asunto. Lo que se narra a continuación es precedido por el marcador de temporalidad interna: "muchos años después". La narración continua dejando atrás la tragedia, y se centra en los diferentes individuos que pueblan la ciudad y forman el cuadro social minero de Marmato: el mecánico gringo eternamente borracho, el animado día del mercado, la descripción erotizada de africanos y mulatos, los accidentes en las minas, el desprecio por los gitanos itinerantes y los celos entre las mujeres mineras. Rasgos de la minería tropical mencionada anteriormente también aparece aquí: Sánchez Gómez pasea al lector a través del colorido mundo de la minería en Marmato permeado por lo sensorial y un afecto colectivo de regocijo común. Pero quizás el más importante de estos acontecimientos es la aparición de Aspasia, la inofensiva pero extraña "bruja de Marmato". Sólo más tarde el lector descubre que Aspasia, la bruja, no es sino Cecilia envejecida que debió perder la razón para luego convertirse en una sombría creatura.

Aspasia aparece algunas veces como una "bruja" benigna que "cura" a los mineros enfermos y realiza hechizos de amor según lo solicitado por las jóvenes mineras. Sólo más tarde, entendemos que el objetivo y motivación de Aspasia es la venganza de su pérdida cuando Mary, una de las jóvenes hijas de un técnico extranjero, aparece en la narración como presa vulnerable de los planes de la bruja. Como vemos, la bruja de las minas, está decidida a recuperar su objeto perdido de su afecto a cualquier costo y como resultado convence a la niñera de Mary para que le entregarle la niña. En este punto se puede apreciar en su totalidad la economía de la violencia ejercida por el deseo de Aspasia de obtener alguna restitución o al menos algún tipo de conclusión para su duelo. El desplazamiento está mediado por el secuestro de Mary, quien a estas alturas en la narración se debería haber parecido mucho a su propia hija Donatila.

El momento de violencia fundacional llega una vez más, no en forma de desalojo de la propiedad, sino en el secuestro por parte de una víctima que intenta de alguna manera recuperar alguna apariencia de totalidad como sujeto. Pero lo novedoso de la novela es que la victimización sucede en la figura de una mujer, en realidad dos mujeres, Aspasia y la niña Mary. Esta victimización - al contrario de las narrativas comunes - no ocurre desplegando el conocido melodrama masculinista basado en abuso sexual y la pérdida del honor; sino en la decisión del autor de involucrarse directamente con la experiencia traumática de una madre causada en parte por una transición forzada e incompleta hacia una modernización impuesta desde afuera. La novela termina cuando Aspasia ya hecha una anciana muere quemada en un incendio causado por ella misma en su choza para evitar así ser encarcelada por el crimen de secuestrar a la pequeña Mary, quien es devuelta por Aspasia a su familia. Así, la novela nos remonta al principio en imágenes simbólicas dicotómicas: la muerte de ambos personajes, Botero y Aspasia, la bruja, quien no era otra que la esposa de Botero, Cecilia; una niña en peligro, en el primer caso la hija de Botero en el segundo, la hija del ingeniero extranjero; $y$, a nivel estructural, los intereses contradictorios de la empresa minera y los trabajadores.

La Bruja de las minas simboliza la crisis y transición del discurso de la minería tropical, donde éste se aleja definitivamente de la idealización de la extracción mineral para dar cabida a intervenciones críticas contra los discursos predominantes de la modernidad y el progreso significado en la expansión de la frontera por el capital extranjero. En las narrativas sobre minerales subsecuentes, la focalización sobre el minero se ocupa de él o ella como significante de la desposesión individual o nacional y no como parte de la metáfora romántica, sujeto-nación. ${ }^{9}$ Después de la violenta expropiación de minas en Marmato, la representación romántica se torna insostenible. Si en Tomás Carrasquilla y Eduardo Zuleta la mina aparece como un espacio de oportunidad y como sitio para discusiones etnográficas, en Sánchez Gómez esta modalidad se ve relativamente desplazada privilegiando discusiones literarias más críticas acerca de la economía política y los paradigmas de modernización que se imponen desde la metrópoli. A nivel local, luego de La bruja de las minas no se escribirá más de minas u oro en Marmato. En el contexto nacional, narrativas mineras como Hombre bajo tierra (1944) de José Antonio Osorio Lizarazo o La rebelión de las ratas (1962) de Fernando Soto Aparicio, representan el fin del discurso tropicalista al asumir los parámetros del realismo social para representar la violencia del capital extranjero y de lo mineros mismos dejando de un lado la perspectiva optimista y exotizante trabajada por Zuleta, Carrasquilla y hasta cierto punto Sánchez Gómez.

Tras el asesinato de Botero, la expulsión de sus socios dueños de minas y la llegada de las empresas extranjeras la dinámica social de la extracción mineral cambia drásticamente. En La bruja de las minas la violencia fundacional de la narración se convierte en el odio de un individuo, en este caso la esposa de Botero, Cecilia -quien se convierte en "la bruja"- dirigido hacia las autoridades locales, el ejército y la compañía extranjera. Esta violencia fundacional, el despojo ilegal y repentino de los propietarios o arrendatarios permite a Sánchez Gómez documentar cómo las diferentes líneas de violencia, que rara vez se conciben como tales, en realidad se extienden efectivamente hasta presente aunque siempre alteradas y reconfiguradas en su trasversar temporal. Sánchez Gómez construye una narración que contiene las huellas de la desposesión y el "robo legal" como fuerzas dentro de un campo específico. Es cierto que 
la violencia fundacional se localiza históricamente en el pasado, pero nunca está completamente superada.

\section{Marmato en el cine: la llegada de los canadienses}

Marmato y la cuestión de la minería disminuye entre las preocupaciones de la élite cultural colombiana y de una clase media cada vez más al tanto de la producción literaria internacional de masas. ${ }^{10}$ No es hasta principios de los años 2000 con una segunda oleada de reformas neoliberales - que abren partes de la economía previamente aisladas a la inversión extranjera- que la atención pública respecto a la cuestión de los derechos de los pequeños mineros y las amenazas ambientales resurge en los debates mediáticos y en textos visuales. Uno de esos textos es el documental Marmato (2014) del director estadounidense Mark Grieco. ${ }^{11}$ Incluyo Marmato en la discusión porque la cinta se sitúa en el actual cruce de extractivismo neoliberal que se vive en Caldas y en Antioquia donde los dos modelos de minería han entrado en contacto haciendo evidente el conflicto de la expansión del capital, la conciencia por lo natural y el impacto sobre los hábitats locales. El film permite una interpretación crítica de la dinámica actual de poder, mientras el conflicto sobre el destino de Marmato se entrelaza inevitablemente al precio internacional de oro y la presión corporativa de los últimos 15 años.

Marmato representa de manera muy elocuente cómo algo tan abstracto como el precio internacional del oro puede determinar el destino de comunidades enteras en el Sur Global. Durante 5 años, Grieco documenta las tensiones que se producen después de que la compañía de mega-minería canadiense Medoro Resources - ahora Gran Colombia Gold - lentamente adquiere los derechos de los propietarios pequeños y medianos, quienes han trabajado esas tierras desde siempre. Grieco muestra la vida cotidiana del pueblo antes de la llegada de la compañía canadiense: los mineros trabajan a salario fijo y no vinculado a la cantidad de oro que extraen, y en su mayoría trabajan bajo sus propias condiciones. Aunque es un trabajo duro es al menos un trabajo estable. Marmato además funciona orgánicamente: esta formado por dos mil personas que viven en la montaña, a poca distancia de las minas que sostienen a sus familias y mantienen fuertes lazos entre si mismos y otras comunidades mineras cercanas. Sin embargo, el conflicto no demora en surgir cuando la administración derechista y favorable a políticas neoliberales de Álvaro Uribe, decide vender los títulos minerales de la zona a intereses corporativos extranjeros lo que resulta en la posibilidad de un desplazamiento radical de la minería tradicional y de la población en general.

En el documental obtenemos acceso a los testimonios de varios Marmateños a favor y en contra de la apertura de la zona a la mega minería corporativa. Resaltamos las intervenciones de José Dumar, el protagonista minero de Marmato y al ingeniero canadiense Lawrence Perks, cuando este último le comenta a los mineros a través de una intérprete cómo la empresa extraería el oro. Perks explica que la comunidad sería probablemente destruida y sólo se emplearía el 30\% de trabajadores. Dumar responde que estas compañías son en realidad hasta peores que las guerrillas del país que desplazan a la gente a través de amenazas y asesinatos. Añade que si sólo se emplea el $30 \%$ ¿qué sucedería entonces con el $70 \%$ restante de la fuerza de trabajo? Perks permanece en silencio. Mas tarde, en otra escena vemos a Perks recorriendo el pueblo y comentándole a la cámara que en realidad se compadece de los locales: "Es triste, destruirán las casas, removerán los cementerios ... es triste pero lo he visto antes, no creo que se den cuenta de lo que sucederá en uno o dos años. ¡Ah mira! Están pintando la iglesia, así que tal vez eso les sirva. Puedes creer en Dios todo lo que quieras, pero no creo que él diga nada si esta montaña es arrasada". ${ }^{12}$ El documental ilustra estas tensiones entre extranjeros y locales, así como la que existe entre marmateños a favor de la exploración y aquellos en contra de manera simple pero efectiva. Estas tensiones desencadenan en olas de protesta y violencia que el documental apenas empieza a registrar pero que ya podemos intuir en épocas de extracción desenfrenada bajo el signo del super-ciclo de las "commodities" y una resistencia mejor informada y mediatizada. El documental no presenta nociones características del discurso de minería tropical estudiadas hasta ahora: no se enmarca el trabajo como goce o exotiza al minero, no se romantiza la causa de los débiles, ni se erotiza al otro. Mas bien dedica su atención a documentar de manera relativamente objetiva las tensiones entre los actores involucrados y las estrategias que cada uno de ellos implementa para movilizar la opinión publica y resaltar las virtudes de su causa. Aunque el film trata de mostrar las cosas "como son" sin presunciones de "reducir" la realidad a una lectura maniquea, resulta claro que se articula como un documento de denuncia que alerta al público sobre las posibles consecuencias de la construcción de la mina a cielo abierto para los ecosistemas naturales y humanos.

Marmato termina sin una conclusión definitiva sobre el destino de la comunidad. Usando texto en pantalla, explica el tipo de relación de los estados canadiense y colombiano en estos proyectos. Se hace hincapié en la complicidad del gobierno canadiense con planes de desarrollo mineros/ energéticos que están inevitablemente ligados a la destrucción de hábitats sociales y naturales enteros en Colombia y en todos los países donde el "desarrollo canadiense" está presente. Y continúa: "Con la ayuda de la Agencia Canadiense de Desarrollo Internacional (Canadian International Development Agency), el gobierno colombiano ha reescrito el código minero del país; las nuevas leyes criminalizan a Dumar y a otros pequeños mineros en Colombia". Grieco cierra su obra con un contemporáneo J'accuse ...! que permanece en la mente de los asistentes. Documentos como Marmato hacen parte de un creciente número de películas y documentales que parecen preocuparse por el 
actual desenvolvimiento del neoliberalismo extractivo en la periferia global y la heterogeneidad que el capital produce y ensambla en textos culturales y discursos subalternos. ${ }^{13}$

El documental diseminó - en el país y en el exteriorun fenómeno que ahora podemos contextualizar económica y literariamente: los conflictos que emergen debido a la búsqueda del oro, la competencia entre modos de producción y la evolución de la creación estética sobre las minas de Marmato. Se pudiera argumentar que el modelo económico basado en "exportación de naturaleza" —altamente tecnificado y profesionalizado en las últimas décadas - continúa siendo el principio que dirige la política económica del país. No argumento que la lógica básica del régimen económico basado en la expansión del capital y los mercados haya cambiado radicalmente, ni que la minería tropical entendida como representación literaria o como una serie de prácticas culturales y sociales concretas en la historia tenga alguna carga normativa o ética que haya que favorecer. El propósito más bien de este estudio es ubicar y describir modos de representación y producción posicionando esta noción como una herramienta para catalogar la formación de una discursividad vis-à-vis la representación de la extracción mineral, como para localizar prácticas culturales económicas que surgen en ciertas partes del país y presentan cualidades diferenciales.

\section{Conclusiones}

Podemos hablar de un "arco de literatura minera" que entra en el siglo XX afectado por corrientes románticas que son evidentes en el tono de Tierra virgen de Zuleta o en el tema de La marquesa de Yolombó de Carrasquilla. Esta trayectoria posteriormente cambia debido a fuerzas externas que alteran radicalmente las relaciones de producción existentes sobre el terreno revelando nuevas tecnologías y ejerciendo nuevas presiones sobre el ser social como es el caso en Marmato.
Este giro hacia la narrativa de denuncia social también fue influenciado por fuerzas literarias externas. Pensemos en las novelas norteamericanas de Upton Sinclair y John Steinbeck. Aunque la literatura colombiana contemporánea escribe poco sobre minas o campos petrolíferos, el impulso por explorar estos micro-mundos no ha desaparecido. ${ }^{14}$ Todo lo contrario, documentos como Marmato y otras producciones contemporáneas revelan el interés que tienen las nuevas generaciones creativas sobre estos temas.

He intentado trazar este arco de la literatura minera en Colombia basándome en la historia de la ciudad de Marmato como arquetipo. Naturalmente, Marmato no es la única ciudad productora de oro en Colombia, mas bien sirve como punto de partida para iniciar la conversación. Desde un punto de vista nacional, este ensayo marca, hasta donde sé, el primer intento de trazar la genealogía de la vida mineral inscrita en prosa y en el cine, donde la categoría de minería tropical sirve para organizar especificidades y particularidades en el complejo y vasto mundo de la representación y la minería. Los autores y cineastas discutidos aquí ayudan a entender la trayectoria de la conciencia crítica del escritor con respecto a las cambiantes prácticas de extraer oro y otros minerales, y como se relacionan con la vida humana y no humana.

Pero las corrientes - literarias y de todo tipo- siempre escapan, incluso el juicio literario más rigoroso, igual que el oro evade las manos de quienes lo buscan en las bateas y se esconde entre los granos. Tal vez por eso la tarea del escritor, al igual que la del crítico, se asemeja a la del minero. Su jornada diaria implica abandonar el mundo de la realidad para entrar en un subterráneo inhóspito en busca de algo, un algo a veces aún sin forma o sentido. Escritor, crítico o minero... este emerge con la esperanza de retornar con ese algo para colocarlo eventualmente en el registro simbólico humano y ayudar a darle sentido a nuevas configuraciones - que permiten y obstruyen al mismo tiempo- interpretación y posicionamiento, afirmación e interpelación, frente a una realidad siempre en formación y flujo.

\section{Notas}

1. Cada forma de explotación genera su propia cultura de resistencia, pero en este caso limito mi discusión a la minería en Colombia. Una catalogación más detallada de la cultura de extracción en los diferentes países de la región requeriría necesariamente otro espacio. Sin embargo, por ahora puedo articular la hipótesis de la Minería Tropical como opuesta de manera desigual a las prácticas de extracción del altiplano andino. En este contexto es necesario recordar que el predominio de la cultura altiplánica en Bolivia, pero también en Perú y Chile, ha determinado prácticas sociales y culturales que difieren radicalmente del resto del continente.

2. En efecto, el Imperio Invisible que French describe tuvo varias sedes en Colombia y en la región. Como objeto de estudio Marmato y el discurso sobre el mismo es el más evidente debido a su potencial como productor de oro (y referente literario), pero también se manifestó en las zonas amazónicas dando lugar a fenómenos como la Fiebre del Caucho, que no solo afectó al país sino a la región Amazónica trastocando radicalmente la vida humana y no humana para siempre. Ver la introducción de Nature, Neo-colonialism, and the Spanish American Regional Writers de Jennifer L. French. También refiérase a Historia contemporánea de América Latina del historiador argentino Tulio Halperín Donghi. 
3. Un texto básico y fundamental es la novela boliviana Socavones de angustia (1947) de Fernando Ramírez Velarde, donde se da cuenta del minero que ha sido violentamente despojado de su Lebenswelt en las comunidades originarias de la sierra o del sistema criollo de producción socioeconómica de la hacienda y reclutado como obrero raso para trabajar por salarios ínfimos y bajo condiciones inhumanas en los desolados campos mineros de Potosí u Oruro; sus condiciones laborales son pésimas y debido al agobiante trabajo que realiza entra en un ciclo de deudas con la empresa, borracheras cada día de pago, y abandono familiar generando un afecto marcado por un pesimismo colectivo y un desasosiego individual debido a la aparenta falta de oportunidades de emancipación social.

4. Hasta la fecha, Remedios y la cercana localidad de Segovia continúan siendo afectadas por la intrusión corporativa y la regulación pro-gran negocio hoy en manos de la misma compañía minera canadiense que causó el conflicto en Marmato, la Gran Colombia Gold Corporation. La ciudad que inspiró a Eduardo Zuleta a escribir sobre su crecimiento en una idílica ciudad minera está en el centro del debate debido a la despiadada adquisición de títulos por pate de Gran Colombia Gold, la criminalización de "guacheros" (mineros despedidos que siguen buscando oro en ahora socavones ajenos y el aumento en militarización por parte todos los actores.

5. Todas las traducciones son mías.

6. La lista de novelas de mercancía en la región es larga. En el contexto de literatura nacional véase La vorágine (1924), de José E. Rivera; Toa: Narraciones de caucherías (1933) y Mancha de aceite (1935), las dos del doctor y escritor paisa César Uribe Piedrahita, y Barrancabermeja: novela de proxenetas, rufianes, obreros y petroleros (1934), del escritor también paisa Rafael Jaramillo Arango.

7. Para entender mejor este cambio en la narrativa colombiana necesitamos unir fragmentos históricos para construir una visión más completa de las convulsiones experimentadas por las masas trabajadoras y rurales de América Latina. En el caso colombiano es justo en esta época que se obtiene un cambio en la administración política y sujeción económica mediada por el evento de la Guerra de los Mil Días. La guerra puede leerse como una clave para entender contextualmente no sólo esta novela sino otras narrativas que surgieron durante el período de la llamada República Liberal (1930-1946). Es durante este período que la generación de centenaristas nacidos entre 1880 y 1895 se vuelven políticamente activos y están marcados por dos acontecimientos dramáticos: primero, el evento de la Guerra de los Mil Días y segundo el alcanzar adultez y conciencia política durante el primer centenario de la independencia en 1910. Estos hombres y mujeres jóvenes que emergieron de la destrucción de la posguerra y de las secuelas indirectas de la Gran Guerra en Europa, como se refleja en la política y la economía internacionales, decidieron hacer avanzar a su nación siguiendo ideales liberales y republicanos. De los cuales el más relevantes hoy día sigue siendo la prevalencia de la "regla de procedimiento civil" con énfasis en la construcción de una sociedad libre y justa. Estos valores pasaron a formar parte de una tradición política que pretendía frenar la voluntad arbitraria de los caudillos que habían arruinado el país a principios y mediados del siglo XIX. En términos de temas internacionales, estos centenaristas -entre los cuales encontramos a Sánchez Gómez y otros- simpatizaban con el movimiento hispano de los Estados Unidos, denominado Hispanismo, que se había originado recientemente para contrarrestar una creciente dominación estadounidense en el Caribe y favorecía la independencia de Cuba y las ideas libertarias de José Martí.

8. En el prólogo de la nueva edición de Jairo Henry Arroyo Reina, se contextualiza históricamente: La bruja de las minas muestra cómo la explotación, el asesinato y la violencia en Colombia no comenzaron con el asesinato de Jorge Eliécer Gaitán en 1948, como lo haría pensar el relato histórico oficial pero tal vez una década o más antes, cuando el despojo violento causado por el capital británico y norteamericano y el abandono sistemático por parte de las autoridades locales habían marcado el país desde el final de la Guerra de los Mil Días hasta los años treinta. Véase también, Los místeres de las minas de Álvaro Gärtner (Editorial Universidad de Caldas), 2005.

9. La vorágine de José E. Rivera publicada en 1924 anticipa un modo de crítica implacable contra el capital no regulado que se extendía sobre la amazona colombiana y peruana. Pero a mi entender, La bruja de las minas es el primer relato que denuncia el abuso hacia pequeños propietarios y trabajadores de las minas en Colombia.

10. Después de las expropiaciones de principios del siglo XX por el gobierno conservador de Rafael Reyes y un estancamiento del precio internacional de oro durante la década de 1920, la minería en la zona disminuyó significativamente. En los años siguientes durante los cuarenta y cincuenta, la narrativa nacional adopta una postura de desencanto y nihilismo marcada por el existencialismo francés, más tarde llamado "nadaismo". En términos generales, podemos argumentar que el movimiento de contracultura nadaista fue dominante hasta la llegada de escritores realistas — y el más tarde catalogado realismo mágico- tras el éxito crítico y comercial de Cien años de Soledad en 1967.

11. 1Marmato es una película documental estadounidense de 2014 escrita, dirigida y producida por Mark Grieco. La película se estrenó en la categoría de Competencia de Documentales de EE. UU. en el Festival de Cine de Sundance 2014, donde obtuvo el "Candescent Award" que reconoce documentales y narrativas que exploran cuestiones sociales. Se puede encontrar en 
Netflix en EE. UU., Canadá, América Latina, Europa y el Reino Unido. Para obtener más información sobre el documental, ver su sitio web en http://www.marmatomovie.com/index.html\#home-slider.

12. Grieco, Mark. 2014. Marmato. Film documental. Calle Films.

13. Entra varias podriamos mencionar el documental peruano Hija de la laguna (2015) de Ernesto Cabellos; La sal de la tierra, coporduccion franco-brasileña de Wim Wenders y Juliano Ribeiro Salgado (2014); y Taromenani 2007 del ecuatoriano Carlos Andres Vera.

14. A mi entender La novia oscura (1999) de Laura Restrepo, es la única novela contemporánea que se ocupa de la subjetividad en un boom town petrolero.

\section{Obras citadas}

Appelbaum, Nancy P. 2003. Muddied Waters: Race, Region, and Local History in Colombia, 1846-1948. Durham: Duke UP.

Botero, Alvaro Pineda. 1999. La fábula y el desastre: Estudios críticos sobre la novela colombiana, 1650-1931. Medellín: Fondo Editorial Universidad EAFIT.

-------. 2001. Juicios de residencia: La novela colombiana, 1934-1985. Medellín: Fondo Editorial, Universidad EAFIT.

Carrasquilla, Tomás. 1981. La Marquesa de Yolombó: Novela del tiempo de la colonia. Medellín: Bedout.

French, Jennifer L. 2005. Nature, Neo-colonialism, and the Spanish American Regional Writers. Hanover, NH: Dartmouth College.

Grieco, Mark. 2014. Marmato. Film documental. Oakland: Calle Films.

Levy, Kurt L. 1980. Tomás Carrasquilla. Boston: Twayne.

Sánchez Gómez, Gregorio. 2010. La bruja de las minas. Bogotá: Ministerio de Cultura.

Sánchez Lozano, Carlos. 1996. Cuentos de Tomás Carrasquilla. Bogotá: Presidencia de la Republica.

Williams, Raymond L. 1991. The Colombian Novel, 1844-1987. Austin: U of Texas.

Zuleta, Eduardo. 1978. Tierra Virgen. Bogotá: Carlos Valencia Editores.

Zuleta, Eduardo. 2015. Tierra Virgen. Medellín: Colección Bicentenario de Antioquia. 